\title{
Comparing Five New Polymer Barriers for the Prevention of Intra-abdominal Adhesions in a Rat Model
}

Citation for published version (APA):

van Steensel, S., Liu, H., Mommers, E. H. H., Lenaerts, K., \& Bouvy, N. D. (2019). Comparing Five New Polymer Barriers for the Prevention of Intra-abdominal Adhesions in a Rat Model. Journal of Surgical Research, 243, 453-459. https://doi.org/10.1016/j.jss.2019.05.043

Document status and date:

Published: 01/11/2019

DOI:

10.1016/j.jss.2019.05.043

Document Version:

Publisher's PDF, also known as Version of record

Document license:

Taverne

Please check the document version of this publication:

- A submitted manuscript is the version of the article upon submission and before peer-review. There can be important differences between the submitted version and the official published version of record.

People interested in the research are advised to contact the author for the final version of the publication, or visit the DOI to the publisher's website.

- The final author version and the galley proof are versions of the publication after peer review.

- The final published version features the final layout of the paper including the volume, issue and page numbers.

Link to publication

\footnotetext{
General rights rights.

- You may freely distribute the URL identifying the publication in the public portal. please follow below link for the End User Agreement:

www.umlib.nl/taverne-license

Take down policy

If you believe that this document breaches copyright please contact us at:

repository@maastrichtuniversity.nl

providing details and we will investigate your claim.
}

Copyright and moral rights for the publications made accessible in the public portal are retained by the authors and/or other copyright owners and it is a condition of accessing publications that users recognise and abide by the legal requirements associated with these

- Users may download and print one copy of any publication from the public portal for the purpose of private study or research.

- You may not further distribute the material or use it for any profit-making activity or commercial gain

If the publication is distributed under the terms of Article $25 \mathrm{fa}$ of the Dutch Copyright Act, indicated by the "Taverne" license above, 


\title{
Comparing Five New Polymer Barriers for the Prevention of Intra-abdominal Adhesions in a Rat Model
}

\author{
Sebastiaan van Steensel, MD, ${ }^{a, b}$ Hong Liu, MD, ${ }^{a, b}$ Elwin H.H. Mommers, MD, PhD, , \\ Kaatje Lenaerts, $\mathrm{PhD},{ }^{a, b}$ and Nicole D. Bouvy, $\mathrm{MD}, \mathrm{PhD}^{a, b, *}$ \\ a Department of Surgery, Maastricht University Medical Centre, Maastricht, The Netherlands \\ ${ }^{\mathrm{b}}$ NUTRIM School of Nutrition and Translational Research in Metabolism, Maastricht University, Maastricht, The \\ Netherlands
}

\section{A R T I C L E I N F O}

\section{Article history:}

Received 18 December 2018

Received in revised form

20 May 2019

Accepted 29 May 2019

Available online 1 August 2019

\section{Keywords:}

Adhesions

Prevention

Polymers

Ischemic button model

Rat model

Abdominal wall

\begin{abstract}
A B S T R A C T
Background: Intra-abdominal adhesions affect up to $93 \%$ of the patients after abdominal surgery, causing small-bowel obstruction, infertility, chronic abdominal pain, and iatrogenic bowel injury at reoperation. The efficacy of five new polymer antiadhesive barriers to avoid adhesion formation is evaluated in an ischemic button model in rats.

Materials and methods: Five new, biodegradable polyurethane and copolyester-based, antiadhesive barriers (A1, A2, A3, B1, and B2) were evaluated in separate experimental groups and compared with two control groups (hyaluronate carboxymethylcellulose barrier and no antiadhesive barrier) in an ischemic button model ( $n=11$ per group operated). After $14 \mathrm{~d}$, the quantity and quality of the adhesions were scored macroscopically. The Kruskal-Wallis with Mann-Whitney U post hoc and the Fisher's exact tests were used for data analysis. The Bonferroni correction method was applied, and a P-value $<0.007$ was considered significant.

Results: Two animals died during surgery and follow-up. A significant reduction of adhesions to ischemic buttons was found in the A2 group (median, 3.5; interquartile range, 2.25) compared with no adhesive barrier (median, 8.0; interquartile range, 2.0$)(P=0.001)$. The remaining groups did not differ significantly regarding adhesion quantity or quality. Adverse events were observed in the A2, A3, and B2 groups.

Conclusions: The A2 antiadhesive barrier reduced the adhesion formation significantly compared with no anti-adhesive barrier, but applicability is questionable because of extensive adverse events observed due to implantation of the anti-adhesive barrier. The Nair score appears not to be sensitive enough to detect differences in adhesion formation in this model. Future research should focus on anti-adhesive barriers that are self-adhering.
\end{abstract}

(c) 2019 Published by Elsevier Inc.

\section{Introduction}

Intra-abdominal adhesion formation is a common complication after abdominal surgery with an incidence reported from
$79 \%$ to $93 \%{ }^{1,2}$ Adhesions cause $56 \%$ of small-bowel obstructions, cause the need for fertility treatment in $23 \%$ of the female patients, and are the most likely cause of chronic abdominal pain in $57 \%$ of the patients with a history of

\footnotetext{
* Corresponding author. Department of Surgery, Maastricht University Medical Centre, PO Box 5800, 6202 AZ Maastricht, The Netherlands. Tel.: +31 43 3875492; fax: +31 433875473 .

E-mail address: n.bouvy@mumc.nl (N.D. Bouvy).

0022-4804/\$ - see front matter @ 2019 Published by Elsevier Inc.
}

https://doi.org/10.1016/j.jss.2019.05.043 
abdominal surgery. ${ }^{3}$ Furthermore, due to adhesions, re-entry to the abdominal cavity is accompanied by an increased risk of iatrogenic bowel injury. ${ }^{3,4}$ Subsequently, this is related to an increase in the incidence of sepsis, intra-abdominal complications, wound infections, a prolonged hospital stay, and higher costs. ${ }^{4}$

The risk of being readmitted $5 \mathrm{y}$ after abdominal surgery because of morbidity directly related to adhesions is $3.8 \%$, with an average readmission rate of 2.2 per patient. ${ }^{5,6}$ This risk is reduced to $3.0 \%$ when a laparoscopic approach is used. ${ }^{7}$ Still, in $37.7 \%$ of the patients, adhesions are observed after laparoscopic surgery, ${ }^{2}$ leaving preventive measures to avoid adhesion formation still of the utmost importance.

Anti-adhesive barriers can be used in the prevention of intra-abdominal adhesions. Oxidized regenerated cellulose (Interceed, Ethicon, US, NJ) showed a reduction of adhesions in gynaecologic patients, but no data regarding the reoperation rate are available. Hyaluronate carboxymethylcellulose (HA-CMC) (Seprafilm, Sanofi, US, NJ) proved to be effective in the reduction of adhesion formation and decreasing the number of reoperations. ${ }^{8}$ HA-CMC reduces adhesion formation in $25.9 \%$ of the cases, ${ }^{9}$ although given the high incidence, further adhesion reduction is desired. These rather unsatisfactory results translate in a low confidence of surgeons toward the use of anti-adhesive barriers in clinical practice, as shown in the Dutch National survey among surgeons. ${ }^{10}$

The lack of a sufficiently effective, preventive measure inspires the search for a new anti-adhesive barrier. Five polymer sheets of different composition are evaluated in this animal study. The aim is to identify the most effective antiadhesive barrier in an ischemic button model in rats in comparison with no anti-adhesive barrier placement and to a currently available anti-adhesive barrier.

\section{Materials and methods}

The study protocol (AVD107002016720) was approved by the ethical committee of animal experiments, which complied to the Dutch Animal Experimental Act and the European Directive 2010/63/EU.

\section{Study design}

The animals were equally divided into seven groups $(n=11$ per group), five intervention groups (A1, A2, A3, B1, and B2) and two control groups (HA-CMC barrier and no adhesive barrier). All groups except for one control group received a $5 \times 5 \mathrm{~cm}$ anti-adhesive barrier, either HA-CMC or one of the interventional barriers. The group receiving HA-CMC was used as a negative control, providing information regarding the effect of the interventional anti-adhesive barriers compared with what is currently available on the market. A computer generated a random sequence regarding the group allocation of the animals. To blind the surgeons, envelopes containing the unmarked antiadhesive barriers were arranged in that sequence. Because two antiadhesive barriers had a rough surface and a positive control group without an antiadhesive barrier was present, complete blinding of the surgeon could not be achieved. During surgery, consequent envelopes were opened and the animal received the barrier accordingly, and in case the animal was allocated to the control group, the envelope was empty. Throughout the experiment, the allocation of the animals remained unknown, so the adhesion assessment at sacrifice and data analysis were performed blindly. The randomization and blinding process were conducted by a researcher not involved in the experiment. The follow-up was $14 \mathrm{~d}$.

\section{Materials}

Five different anti-adhesive barriers (A1, A2, A3, B1, and B2) were evaluated for their anti-adhesive properties. Three barriers were based on a linear, segmented biodegradable polyurethane (A1, A2, and A3). A1 and A2 were different in their hard segment composition, and $\mathrm{A} 3$ was enriched with bioactive glass particles on one side. Two barriers consisted of a high molecular weight bioresorbable copolyester called poly (DL-lactide- $\varepsilon$-caprolactone) (B1 and B2). B2 had a rough surface on one side to promote ingrowth in the abdominal wall and prevent migration. The experimental barriers were supplied by the manufacturer (Polyganics, Groningen, The Netherlands) in the appropriate size, $5 \times 5 \mathrm{~cm}$, except for B1 which was supplied in a size of $7 \times 5 \mathrm{~cm}$ and cut to size under sterile conditions. HA-CMC (Seprafilm) was purchased and used according to the manufacturer's instructions. It was cut to a size of $5 \times 5 \mathrm{~cm}$ under sterile conditions.

\section{Animals}

Seventy seven adult, male Wistar rats with a body weight between 200 and $250 \mathrm{~g}$ were obtained from a registered breeding company (Envigo, Horst, The Netherlands) and housed at the central animal facilities of Maastricht University. The animals had free access to food and water, were socially housed with a 12-h dark-light cycle, and cared for according to local protocol.

\section{Operative procedure}

Preoperatively, all animals received buprenorphine $0.05 \mathrm{mg} /$ $\mathrm{kg}$ and carprofen $4 \mathrm{mg} / \mathrm{kg}$ via subcutaneous injections. Anesthesia was induced with 3\%-4\% isoflurane using an induction chamber. Anesthesia was maintained with $2 \%$ isoflurane. The abdomen was shaved and disinfected with a chlorhexidine solution. The abdomen was opened through a midline incision of approximately $6 \mathrm{~cm}$. On each side of the midline incision, four ischemic buttons were created, $1 \mathrm{~cm}$ lateral of the incision and $1 \mathrm{~cm}$ apart. ${ }^{11-14}$

After creating the buttons, a previously designated experimental barrier, HA-CMC barrier or no barrier was placed according to the randomization. Two barriers (A3 and B2) had one roughened side that was placed facing the abdominal wall. All barriers were fixed to the abdominal wall with two lateral 4-0 polypropylene sutures (Prolene, Ethicon, Johnson \& Johnson, Somerville, NJ) placed in the middle of the barrier on both sides. In case of no barrier placement or an impossibility to fixate by suture, like with HA-CMC barrier which is selfadhesive, two 4-0 polypropylene sutures (Prolene, Ethicon, Johnson \& Johnson, Somerville, NJ) were placed in the 
abdominal wall lateral of the ischemic buttons. This location corresponds with the fixation of the barrier in the intervention groups.

The abdominal wall was closed with a continuous 4-0 polyglactin suture (Vicryl, Ethicon, Johnson \& Johnson, Somerville, NJ), and the skin was closed intracutaneously with a 40 absorbable suture (Monocryl, Ethicon, Johnson \& Johnson, Somerville, NJ).

At the time of sacrifice, the animals were brought under anesthesia according to the previously described protocol, and the abdomen was opened through the scar of the previous midline incision. The adhesions were scored macroscopically, and afterward, the animals were sacrificed by cardiac puncture.

\section{Adhesion scoring}

The adhesions were scored macroscopically using the Nair scoring system for adhesion scoring. ${ }^{15}$ Furthermore, tenacity (Zühlke score) and vascularization of the adhesions were scored (see Table 1). ${ }^{16}$ The number of ischemic buttons involved in adhesions and the organ involvement were recorded separately.

\section{Statistical analysis}

A power calculation was performed, based on the Nair score, estimating an effect size of $20 \%$ with a variance of $16 \%$. To achieve a power of 0.80 with an alfa of 0.05 (two-sided test), groups of 11 animals are needed. No drop-out was expected. Nonparametric testing was performed, using the Kruskal-Wallis test with a post hoc Mann-Whitney U-test for continuous variables. For nominal variables, a Fisher's exact

\section{Table 1 - Adhesion scoring systems. ${ }^{16}$}

\begin{tabular}{|c|c|c|}
\hline \multirow[t]{5}{*}{ Nair score } & Grade 0 & $\begin{array}{c}\text { No adhesions/insignificant } \\
\text { adhesions }\end{array}$ \\
\hline & Grade 1 & $\begin{array}{c}\text { Only one adhesions band between } \\
\text { the organs or between one organ } \\
\text { and the abdominal wall }\end{array}$ \\
\hline & Grade 2 & $\begin{array}{c}\text { Two adhesions bands between } \\
\text { organs or between one organ and } \\
\text { the abdominal band }\end{array}$ \\
\hline & Grade 3 & $\begin{array}{c}\text { More than two adhesion bands } \\
\text { between the organs or between one } \\
\text { organ and the abdominal wall or } \\
\text { adhesions of the intestinal loops } \\
\text { without any adhesion to the } \\
\text { abdominal wall }\end{array}$ \\
\hline & Grade 4 & $\begin{array}{l}\text { Adhesions of all viscera to the } \\
\text { abdominal wall }\end{array}$ \\
\hline \multirow[t]{4}{*}{ Zühlke score } & Grade 0 & No adhesions \\
\hline & Grade 1 & Filmy adhesions, blunt dissection \\
\hline & Grade 2 & Strong adhesions, sharp dissection \\
\hline & Grade 3 & $\begin{array}{l}\text { Very strong vascularized } \\
\text { adhesions, sharp dissection, } \\
\text { damage hardly preventable }\end{array}$ \\
\hline Vascularization & Yes/no & \\
\hline
\end{tabular}

test was used. Bonferroni correction method was applied to correct for multiple testing; the corrected significance limit was a $P^{*}<0.007(0.05 / 7)$.

\section{Results}

Two rats deceased before the end of the study, one during anesthesia and one during follow-up. The mean preoperative weight was 237.5 gram (SD, 11.5 gram) and did not significantly differ between groups $(P=0.711)$.

\section{Operative procedure}

One of the two deceased animals was allocated to the A1 group and died during anesthesia, by cardiac failure, based on autopsy. In the remaining 76 animals, operative procedures were carried out as planned.

The ease of placement of the different anti-adhesive barriers depended on the different materials. B1 appeared to stick to oneself causing difficulty handling the barrier, which complicated intra-abdominal placement. Using the A1 barrier, similar problems were encountered, with curling of the barrier. B2, A3, and A2 were considered easy to handle, although the suturing of $A 2$ to the abdominal wall caused tearing of the barrier in two cases.

\section{Follow-up}

The second deceased animal was randomized in the A2 group and was found dead in its cage on the second day postoperatively. No clear cause of death was found, but there were no signs of ileus, perforation, hemorrhage, or intra-abdominal infection at autopsy. In the remaining animals, no complications occurred during follow-up and all completed the 14-day period without reaching humane endpoints.

\section{Macroscopic evaluation}

At sacrifice, the intra-abdominal cavity was inspected, findings were recorded, and remnants of the anti-adhesive barrier were examined. A high occurrence of folding of the barrier was observed in the groups receiving the B1, B2, and A1 barriers (see Table 2). In 8 of 11 cases, the A2 barrier was torn or fragmented at sacrifice, which was also encountered in one animal after placement of B2.

An extensive adverse reaction was found in one animal in the A2 group. The barrier was encapsulated in a pocket in the abdominal wall extending along the midline incision. This pocket was filled with serous fluid and fibrotic tissue encapsulating the complete but torn A2 barrier (see Fig. 1). The A3 barrier caused an adverse reaction in three animals. One animal showed an abnormal amount of serous intra-abdominal fluid, and one animal presented with thickening and hardening of the abdominal wall caused by fibrotic tissue. In the third animal, a barrier encapsulated by fibrotic tissue, serous intra-abdominal fluid and completely adhesive intestines were encountered. Two rats in the $\mathrm{B} 2$ group developed a mild reaction with a single cyst on the barrier. 
Table 2 - Results of macroscopic evaluation presented as median with IQR or percentage of occurrence.

\begin{tabular}{|c|c|c|c|c|c|c|c|c|}
\hline Scoring systems & A1 & A2 & A3 & B1 & B2 & $\begin{array}{l}\text { HA-CMC } \\
\text { barrier }\end{array}$ & Control & $P$ \\
\hline Nair score median (IQR) & $3.0(0.0)$ & $3.0(1.0)$ & $3.0(0.5)$ & $3.0(0.0)$ & $3.0(0.0)$ & $3.0(1.0)$ & $3.0(0.0)$ & 0.274 \\
\hline Zühlke score Median (IQR) & $2.0(1.0)$ & $1.0(1.25)$ & $2.5(2.0)$ & $3.0(2.0)$ & $1.0(1.0)$ & $1.0(1.0)$ & $2.0(1.0)$ & 0.330 \\
\hline $\begin{array}{c}\text { Vascularization } \\
\text { yes/total (\%) }\end{array}$ & $4 / 9(44.4 \%)$ & $2 / 10(20.0 \%)$ & $6 / 11(54.5 \%)$ & $8 / 11(72.7 \%)$ & $2 / 11(18.2 \%)$ & $3 / 11(27.3 \%)$ & $6 / 11(54.5 \%)$ & 0.086 \\
\hline $\begin{array}{l}\text { Number of buttons } \\
\text { Median (IQR) }\end{array}$ & $5.0(4.5)$ & $3.5(2.25)$ & $4.0(2.25)$ & $6.0(2.0)$ & $5.0(3.0)$ & $6.0(2.0)$ & $8.0(2.0)$ & 0.004 \\
\hline $\begin{array}{l}\text { Number of organs involved } \\
\text { in adhesions Median } \\
\text { (IQR) }\end{array}$ & $2.0(1.0)$ & $1.5(2.0)$ & $2.0(1.5)$ & $2.0(0.0)$ & $2.0(1.0)$ & $3.0(2.0)$ & $3.0(1.0)$ & 0.204 \\
\hline
\end{tabular}

- = not observed.

$P<0.004$ is considered significant.

In the HA-CMC barrier group, two cases showed an unexpected adverse reaction, one animal showed an inflammatory response in the abdominal wall at sacrifice. In the other animal, a cavity made up of fibrotic tissue of $2 \mathrm{~cm}$ in diameter was encountered distal in the midline incision, which could be explained by a foreign body response although the HA-CMC barrier completely dissolved.

\section{Adhesion assessment}

Adhesions were scored according to the protocol; results are described in Table 2 .

\section{Quantity of adhesions}

The median Nair score was 3.0 in all groups, with only differences in the interquartile ranges (IQRs) $(P=0.274)$. The number of ischemic buttons involved in adhesions was the highest in the control group without an anti-adhesive barrier with a median of 8.0 (IQR, 2.0), followed by HA-CMC barrier and B1 with both a median of 6.0 ischemic buttons involved (IQR, 2.0). In $B 2, A 1$, and $A 3,5.0$ (IQR, 3.0), 5.0 (IQR, 4.5), and 4.0 (IQR, 2.25) buttons were involved, respectively. The number of buttons involved in adhesions was significantly lower in the A2 group (median, 3.5; IQR, 2.25) than the control group $(P=0.001)$ and B1 group $(P=0.003)$ but showed no significant difference compared with the HA-CMC barrier group $(P=0.009)$. All other comparisons between groups did not reach statistical significance (see Fig. 2).

The number of organs involved in adhesions was recorded as a measure of the extent of adhesion formation, but no significant difference between groups was encountered $(P=0.204)$. One animal in the A2 group showed an adverse reaction to the anti-adhesive barrier and subsequently
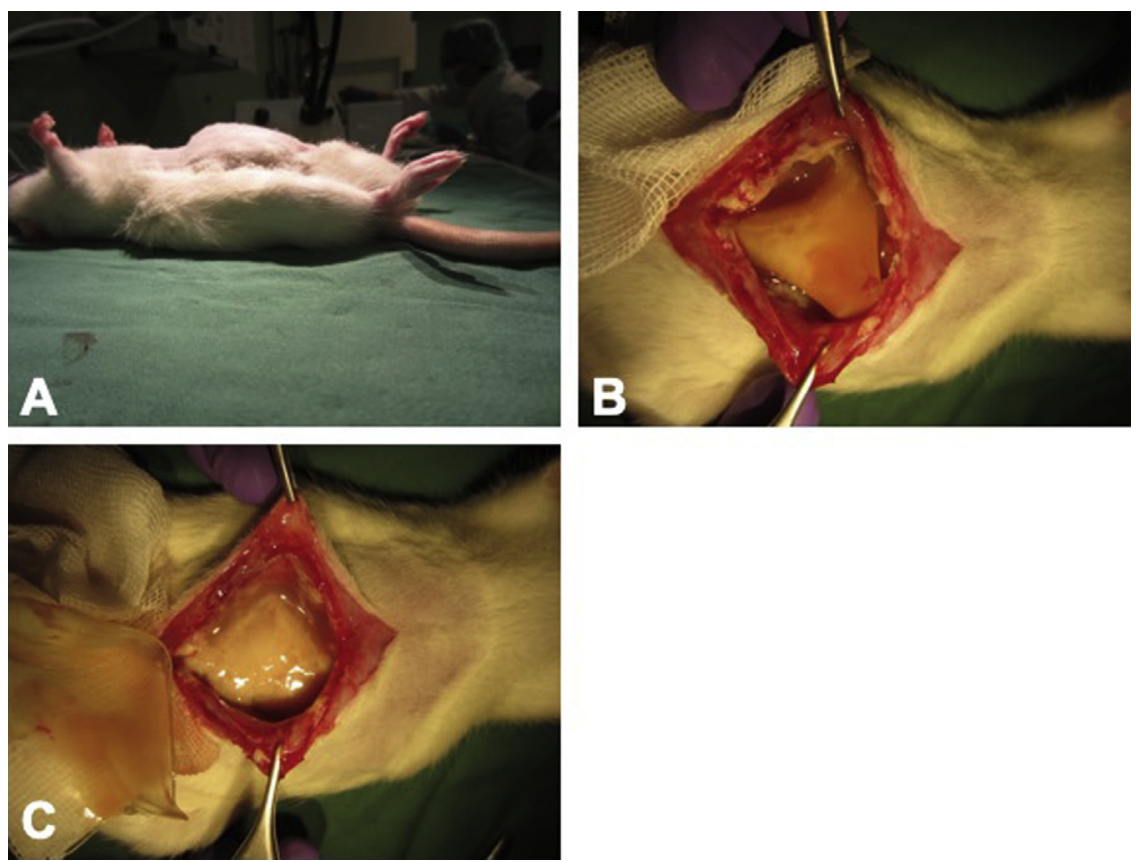

Fig. 1 - One case of a foreign body response in a rat, $14 \mathrm{~d}$ after implantation of the A2 barrier. (A) Macroscopic evaluation $14 \mathrm{~d}$ after surgery, (B) encapsulated barrier encountered after midline incision, (C) cavity filled with fibrotic tissue and serous fluid after removal of the A2 barrier. (Color version of figure is available online.) 


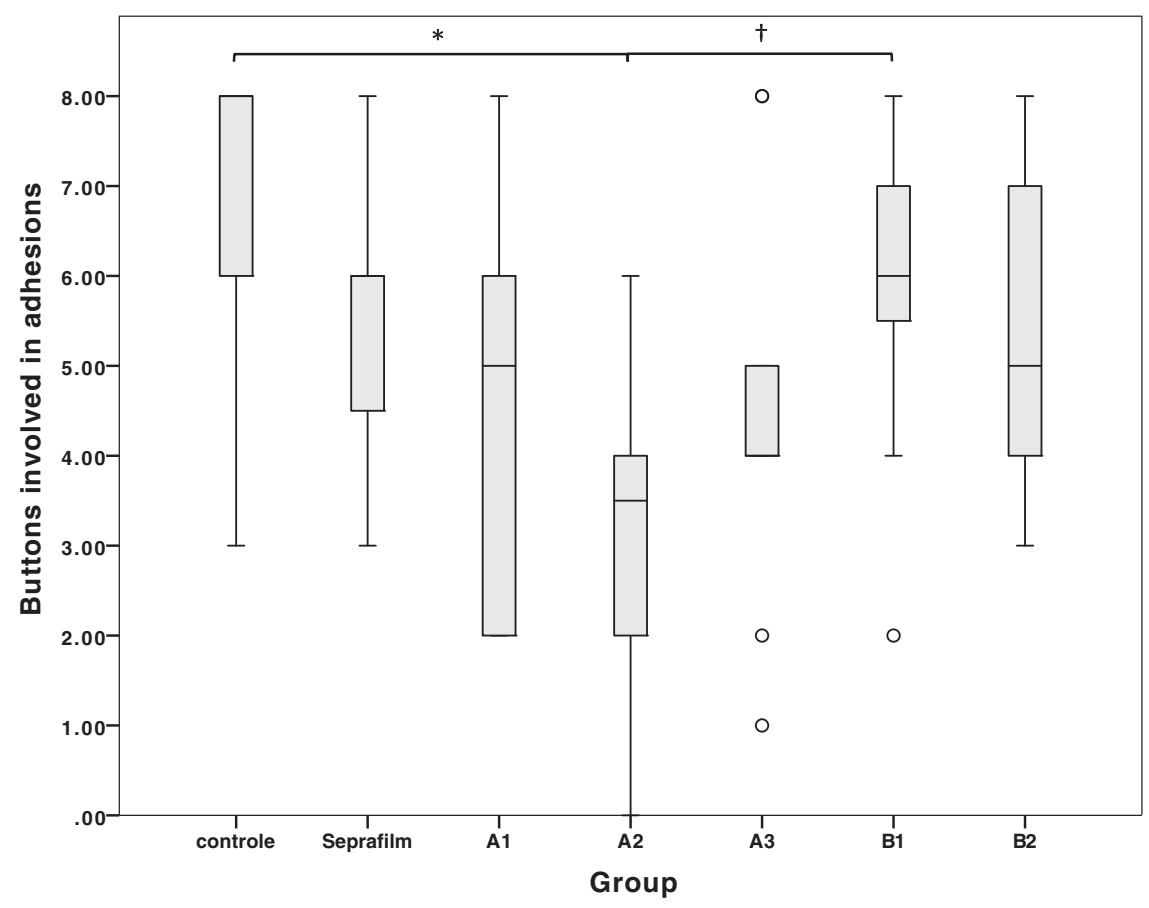

Fig. 2 - Tukey's box plot of number of ischemic buttons involved in adhesion and median with interquartile ranges. Statistics were performed using the Kruskal-Wallis test with a post hoc Mann-Whitney U-test. $P^{*}<0.007$ is considered significant. ${ }^{*} P=0.001 ; \nmid P=0.003$.

received the maximum Nair score, but all ischemic buttons were incorporated in the pocket encapsulating the anti-adhesive barrier. Two of three animals in the A3 group that showed an adverse reaction were scored the maximum Nair score, and eight of eight buttons were involved in adhesions.

\section{Quality of adhesions}

The median Zühlke score of the adhesions was 3.0 (IQR 2.0) in the B1 group, 2.5 (IQR 2.0) in the A3 group, and 2.0 (IQR 1.0) in both the control and the A1 group. A2, B2, and HA-CMC barriers all scored a median of 1.0 with an IQR of 1.25, 1.0, and 1.0, respectively. No significant differences were found between the groups regarding the Zühlke score $(P=0.330)$, as well as the vascularization of the adhesions $(P=0.086)$. One animal in the A2 group and two animals in the A3 group that were associated with an adverse reaction all scored the maximum Zühlke score.

\section{Discussion}

The burden of adhesions continues to trouble patients after abdominal surgery, not only by complications occurring long after the first operation but also by increasing the risk of complications during reoperation. ${ }^{1-4}$ Unfortunately, the laparoscopic approach does not provide a satisfactory reduction in adhesion formation, ${ }^{2}$ and available anti-adhesive barriers fail to produce effective adhesion prevention. ${ }^{8,9}$ Therefore, the search for efficient prevention of adhesion formation is still of great importance.
The adhesions in this animal experiment were scored on two main characteristics; the quantity and quality of the adhesions. The Nair score was used for the evaluation of the quantity of adhesions but failed to distinct between groups. This might be caused by the ischemic button model itself, which induces extensive adhesion formation, leading in almost all cases to a Nair score of three (more than two adhesion bands present). The same has been described in a previous report. ${ }^{14}$ The Nair score lacks finesse in this model in contrast to for instance the cecal abrasion model, where a more confined area is scored for adhesions. Scoring the four quadrants of the abdomen separately would increase the precision but would also allow room for error because of the small size of the abdomen of the rat.

The number of buttons involved in adhesions appears to be a more suitable outcome for adhesion evaluation in this model. The fact that the median number of buttons involved in adhesions was eight of eight buttons in the control group proves that the ischemic button model is sufficiently adequate in adhesion induction. The A2 barrier showed a significantly lower number of ischemic buttons involved in adhesions than no anti-adhesive barrier and the B1 barrier. Regarding the quality of the adhesion, the Zühlke score, and vascularization of the adhesions, we could not detect any significant differences between groups.

Based on the lower number of buttons involved in adhesions in the A2 group, a better performance regarding adhesion reduction can be concluded. In three antiadhesive barriers, A2, A3, and B2, an adverse reaction was encountered at sacrifice. In the B2 and in two cases of the A3 group, the adverse reaction could be classified as mild. But in one case in the $\mathrm{A} 3$ and the $\mathrm{A} 2$ group, an extensive adverse reaction 
occurred with encapsulation of the barrier. In addition, one of the animals in the A2 group was found dead during follow-up and no cause of death could be established. This could be an incidental finding, but a relation to the implantation of the A2 barrier cannot be ruled out. In case of the latter, two adverse reactions related to $\mathrm{A} 2$ implantation were recorded. B2 had a sanded surface on one side to promote attachment to the abdominal wall, and A3 was enriched with bioactive glass to enhance antibacterial qualities. Interestingly, these two barriers both had a rough surface facing the abdominal wall, which might be involved in the development of an adverse reaction.

There are limitations to this study worth mentioning. Despite all measures to ensure random allocation, blinding of allocation, and blind outcome assessment, the nature of the different sheets and control groups rendered absolute blinding impossible, which could be a source for bias. All anti-adhesive barriers investigated were not self-adherent and in need of additional fixation. The barrier was fixated with two nonabsorbable sutures positioned midlateral at the barrier. Sutures as a fixation method are known to induce adhesions in the presence of an already damaged peritoneum. ${ }^{17}$ Nonabsorbable sutures are equally associated with intraabdominal adhesions in terms of incidence and severity compared with absorbable sutures when used for mesh fixation after 1 week follow-up. ${ }^{18}$ In this experiment, two nonabsorbable sutures were placed in all intervention groups, including in the self-adherent HA-CMC barrier group, equalizing the adhesion-inducing effect of sutures. The lack of selfadhering qualities of the investigated barriers allows for space between the barrier and the abdominal wall, which can be occupied by mobile organs such as the omentum or scrotal fat. The anti-adhesive barrier function is bypassed, and adhesions are allowed to form.

The positioning of the sutures midlaterally in the barrier is also a point of discussion. The use of more sutures, such as one in every corner, would induce more adhesions interfering with the model, but the two-suture fixation method allowed for folding of the barrier. This kind of migration of the barrier might disadvantage the coverage of the ischemic buttons and reduce the anti-adhesive barrier function.

The HA-CMC barrier performed equally and, in most cases, worse than the intervention barriers, which was unexpected. Especially, regarding the number of ischemic buttons and organs involved in adhesions, the HA-CMC barrier did not achieve the anticipated results. The ischemic button might be a very fiercely adhesion-inducing model overstraining the anti-adhesive capacity of the HA-CMC barrier. In a previous report, however, significant adhesion reduction by a $5 \times 7 \mathrm{~cm}$ HA-CMC barrier in an ischemic button model in a comparable setting was accomplished. Despite the difference in size, adequate covering of the ischemic buttons was achieved in this experiment. Placing eight buttons instead of six appears to be of high impact on the adhesion formation. ${ }^{19}$

\section{Conclusion}

The A2 barrier showed a significant reduction in adhesion formation in contrast to the remaining four polymer anti- adhesive barriers tested in this ischemic button model. The encountered extensive adverse events in the A2 group raise serious doubt on its applicability. The Nair score lacks sensitivity and appears inappropriate for adhesion assessment in the ischemic button model. Given the adhesioninducing capacities of suture material and chance of migration, future studies might focus on the self-adhering properties of barriers.

\section{Acknowledgment}

The study was supported by Netherlands Organization for Health Research and Development (ZonMw grant "More Knowledge with Fewer Animals" project number 114024053 Polyganics, Groningen, The Netherlands); Medical technology company.

Authors' contributions: H.L. and E.M. were involved in the design, the writing of the study protocol, and execution of the experiment. S.v.S. conducted the experiment, analyzed the data, drew conclusions, and wrote the article. L.K. supervised the project and provided rigorous feedback on the manuscript. N.B. was involved in the conception of the study, supervised the entire project, and approved the final manuscript.

\section{Disclosure}

This research received funding from Polyganics (Groningen, The Netherlands) for acquisition of the required materials, animals, and associated costs. All authors declare no conflicts of interest, are all employed by academic medical centers or the university, and have no financial ties to Polyganics (Groningen, The Netherlands). Polyganics (Groningen, the Netherlands) produced the antiadhesive barriers but was not involved in the design or conduct of the experiment or in the gathering or interpretation of the data.

\section{R E F E R E N C E S}

1. Menzies D, Ellis H. Intestinal obstruction from adhesionshow big is the problem? Ann R Coll Surg Engl. 1990;72:60-63.

2. Stommel MW, Ten Broek RP, Strik C, et al. Multicenter observational study of adhesion formation after open-and laparoscopic surgery for colorectal cancer. Ann Surg. 2017;267:743-748.

3. Ten Broek RP, Issa Y, van Santbrink EJ, et al. Burden of adhesions in abdominal and pelvic surgery: systematic review and met-analysis. BMJ. 2013;347:f5588.

4. ten Broek RP, Strik C, Issa Y, Bleichrodt RP, van Goor H. Adhesiolysis-related morbidity in abdominal surgery. Ann Surg. 2013;258:98-106.

5. Parker MC, Ellis H, Moran BJ, et al. Postoperative adhesions: ten-year follow-up of 12,584 patients undergoing lower abdominal surgery. Dis Colon Rectum. 2001;44:822-829 [discussion 9-30].

6. Parker MC, Wilson MS, Menzies D, et al. The SCAR-3 study: 5year adhesion-related readmission risk following lower abdominal surgical procedures. Colorectal Dis. 2005;7:551-558. 
7. Andersen P, Jensen KK, Erichsen R, et al. Nationwide population-based cohort study to assess risk of surgery for adhesive small bowel obstruction following open or laparoscopic rectal cancer resection. BJS Open. 2017;1:30-38.

8. ten Broek RP, Stommel MW, Strik C, van Laarhoven CJ, Keus F, van Goor $\mathrm{H}$. Benefits and harms of adhesion barriers for abdominal surgery: a systematic review and meta-analysis. Lancet. 2014;383:48-59.

9. Kumar S, Wong PF, Leaper DJ. Intra-peritoneal prophylactic agents for preventing adhesions and adhesive intestinal obstruction after non-gynaecological abdominal surgery. Cochrane Database Syst Rev. 2009:CD005080.

10. van Steensel S, van den Hil LCL, Schreinemacher MHF, Ten Broek RPG, van Goor H, Bouvy ND. Adhesion awareness in 2016: an update of the national survey of surgeons. PLoS One. 2018;13:e0202418.

11. Kraemer B, Wallwiener C, Rajab TK, Brochhausen C, Wallwiener M, Rothmund R. Standardised models for inducing experimental peritoneal adhesions in female rats. Biomed Res Int. 2014;2014:435056.

12. Rajab TK, Wauschkuhn CA, Smaxwil L, Kraemer B, Wallwiener M, Wallwiener CW. An improved model for the induction of experimental adhesions. J Invest Surg. 2010;23:35-39.
13. Whang SH, Astudillo JA, Sporn E, et al. In search of the best peritoneal adhesion model: comparison of different techniques in a rat model. J Surg Res. 2011;167:245-250.

14. Mommers EH, Hong L, Jongen A, Bouvy ND. Baseline performance of the ischaemic button model for induction of adhesions in laboratory rats. Lab Anim. 2018;53:63-71.

15. Nair SK, Bhat IK, Aurora AL. Role of proteolytic enzyme in the prevention of postoperative intraperitoneal adhesions. Arch Surg. 1974;108:849-853.

16. Zuhlke HV, Lorenz EM, Straub EM, Savvas V. [Pathophysiology and classification of adhesions]. Langenbecks Arch Chir Suppl II Verh Dtsch Ges Chir. 1990:1009-1016.

17. Wallwiener CW, Kraemer B, Wallwiener M, Brochhausen C, Isaacson KB, Rajab TK. The extent of adhesion induction through electrocoagulation and suturing in an experimental rat study. Fertil Steril. 2010;93:1040-1044.

18. Schreinemacher $\mathrm{MH}$, van Barneveld KW, Peeters E, et al. Adhesions to sutures, tackers, and glue for intraperitoneal mesh fixation: an experimental study. Hernia. 2014;18:865-872.

19. Vogels RR, Bosmans JW, van Barneveld KW, et al. A new poly(1,3-trimethylene carbonate) film provides effective adhesion reduction after major abdominal surgery in a rat model. Surgery. 2015;157:1113-1120. 